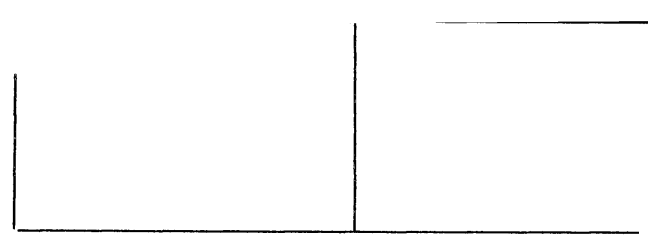

Rev. Latinoam. Psicopat. Fund., IX, 2, 300-317

\title{
Tempo, idade e cultura: uma contribuição à psicopatologia da depressão no idoso. Parte III:
} A depressão, o tempo e a cultura

\author{
Cláudio Lyra Bastos
}

\begin{abstract}
Procuramos aqui relacionar dois aspectos fundamentais das intuições culturais sobre a passagem do tempo - a temporalidade cíclica e a contínua - com a terapêutica médica e especialmente com a psicopatologia, numa visão crítica do constructo moderno da depressão no idoso. Inspirado em perspectivas de natureza antropológica, o texto se apóia na experiência clínica cotidiana e na atitude fenomenológica que orienta essa prática. Nas concepções culturais que tendem a perceber a passagem do tempo de forma predominantemente cíclica, o envelhecer é parte de um movimento eterno e a família se perpetua em seus descendentes, nas suas tradições, no vínculo com a terra ou no exercício do ofício familiar. As transformações culturais que têm proporcionado a passagem para enfoques mais direcionais do tempo vão destacando cada vez mais o papel individual na história social. Quanto mais difícil for a passagem de Weltanschauungen tradicionais, de tendência circular, fatalista, repetitiva e eterna para outras de tendência individualizante, burocratizante, planejadora e sucessiva, maiores as dificuldades para uma senectude satisfatória e maior a tendência à medicalização desse fracasso. Esta é a terceira parte de uma série de três artigos.
\end{abstract}

Palavras-chave: Psicopatologia e cultura, temporalidade e medicina, depressão no idoso, psicogeriatria 
primeiro autor, Sudbo afirmava que antiinflamatórios não esteróides - aspirina, por exemplo - reduzem incidência de câncer na boca, mas aumentam o risco de morte associada a doenças cardiovasculares. A conclusão, segundo o texto, advinha da identificação e análise de 908 pessoas, das quais 454 com câncer na boca e 454 "controles". Essas pessoas foram localizadas na base de dados CONOR - sigla para Coorte da Noruega.

Sudbo descreveu a composição do grupo: gênero, idade, se fumava ou não. Em dados não publicados no artigo, relacionou também a data de nascimento de cada uma das 908 pessoas. Nenhuma das 908 pessoas existe - Sudbo inventou tudo. A 250 delas, o oncologista atribuiu a mesma data de nascimento. Todos os seus artigos estão sendo investigados, e a Lancet já retirou o de 2005. Um ensaio clínico em parte baseado nos resultados desse artigo, financiado pelo National Cancer Institute, poderá vir a ser suspenso. A fraude foi descoberta porque o acesso à base de dados em que Sudbo disse ter buscado seus 908 casos ainda não estava aberto a pesquisadores.

Sudbo admitiu a invenção, e foi demitido. Encerrou assim a sua carreira, aos 44 anos.

Tendência

A vida imortal de Henrietta Lacks - esse livro, escrito por Rebecca Skoot, chegará às livrarias dos EUA em 2007. Nele, a autora conta a história da primeira linhagem de células humanas criada em laboratório, e seu objetivo é discutir o uso que a medicina e os pesquisadores em medicina fazem de tecidos retirados de todos nós em exames clínicos. De acordo com ela, o único relatório sobre o assunto, feito pela Rand Corporation, conclui haver, em 1999, $307 \mathrm{mi}$ lhões de amostras de sangue e células diversas humanas estocadas nos Estados Unidos, retiradas de 178 milhões de pessoas. Um dos aspectos da questão é que, em muitos casos, essas amostras resultam em descobertas que enriquecem pesquisadores e laboratórios. Outro aspecto é: a quem pertencem esses tecidos? As pessoas de quem foram retirados têm direito sobre eles, e sobre o uso que será feito deles? Skoot relatou, na revista do New York Times, que pesquisas qualitativas já mostram um sentimento crescente de oposição à liberdade atual dos cientistas. Estes já se preocupam: células são uma espécie de matéria-prima da pesquisa - e se, agora, os doadores de tecidos decidem dizer: "minhas células podem ser usadas para investigar isto, mas não aquilo"? A pesquisa pode parar... e é ela, crê a cultura ocidental, que sustenta a esperança no "avanço" permanente da medicina, aquele que - supostamente - vai afastar para mais longe dos humanos a certeza da morte. 


\section{Cultura, envelhecimento e morte}

Tempus edax rerum, tuque, invidiosa vetustas, Omnia destruitis!

(Tempo consumidor de todas as coisas, e tu, invejosa velhice, tudo destruídes!)

Ovídio, As metamorfoses, XV, 234

O tema do envelhecimento e da morte não é estranho a nenhuma sociedade humana, e sempre esteve presente nos contos, mitos e representações teatrais desde a antiguidade. Todas as tradições folclóricas e mitologias têm algo a dizer sobre o assunto (Bastos, 2005, 2006).

De acordo com a antiga tradição budista, o príncipe Siddharta Gautama partiu em busca da verdade após ter sido confrontado com quatro visões conturbadoras. A primeira delas foi precisamente a de um homem velho, em franca decrepitude.

$\mathrm{Na}$ mitologia grega temos diversos mitos referentes ao destino do homem. Na Teogonia, após guerra dos Titãs e a deposição de Cronos por Zeus, instala-se uma nova era, em que o tempo agrícola vai sendo substituído pelo tempo urbano. Como já foi mencionado, as lutas de Héracles, filho de Zeus, contra Anteu, filho de Gea, a Terra, e contra Busíris, do Egito, que capturavam os estrangeiros (comerciantes) que aportavam em suas terras e os sacrificavam às divindades telúricas para obterem fertilidade na produção agrícola, representam simbolicamente essa época de mudanças.

As Moiras - Cloto, a fiandeira; Lachesis, a medidora; e Atropos, que corta o fio da vida - eram divindades responsáveis por cada vida humana, conhecidas como As Parcas pelos romanos. No célebre enigma da Esfinge, solucionado por Édipo, propõe-se o homem como o animal que anda com quatro pernas pela manhã, duas ao meio dia e três à noite. 


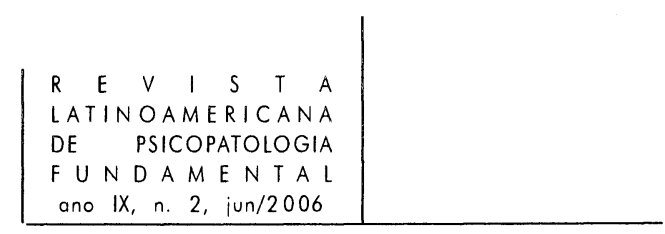

Desfecho irônico teve o caso da deusa da aurora, Eos, que se apaixonou por um jovem mortal, Titon, e pleiteou que fosse dada ao rapaz a imortalidade. Zeus concedeu o pedido, negando-lhe porém a eterna juventude. Assim Eos acabou ficando com um amante imortal, mas decrépito. A dramática história de Medéia e Jasão envolve também o caso do rei usurpador Pélias. Sendo Medéia uma feiticeira e conhecendo uma fórmula de rejuvenescimento, persuadiu as filhas de Pélias a aplicá-la no velho pai. Mas o tal procedimento consistia em cortar o sujeito em pedaços e fervê-lo numa mistura de ervas. Naturalmente, não deu certo, deixando as pobres moças arcarem com o crime de parricídio. Na peça teatral Alceste, de Eurípides, vemos o diálogo ferino entre o rei Admeto, que não queria deixar a vida ainda jovem, e seu pai, que, mesmo velho, não via por que devesse morrer pelo filho, já lhe tendo dado a existência.

Dessa forma, vemos que a velhice, a decrepitude e fim da vida nunca deixaram de ser fatos angustiantes, ou pelo menos desagradáveis, para todas as pessoas, em todas as épocas. No entanto, certas formas de se perceber a passagem do tempo podem dar outros sentidos à existência e tornar os seus momentos finais senão felizes, ao menos mais dignos e serenos.

\section{O tempo cíclico e o envelhecimento}

$\mathrm{Na}$ tradição hebraica, vemos os patriarcas, os juízes, os profetas, serem vistos como personagens eternos e recorrentes, assim como estava escrito que todos os povos de Israel já se encontravam no seio de Abraão. Como os gerontes gregos, os idosos tinham uma imagem de respeitabilidade, e até hoje, devido às expressões bíblicas, certos grupos religiosos cristãos usam o termo "ancião" para estabelecer respeitabilidade e autoridade, independente da idade. No entanto, já mencionamos que a primeira marcação artificial do tempo, independente da natureza, surgiu entre os judeus.

Os patronímicos, partículas nominais que significam filho de-, existentes até hoje em línguas eslavas, e remanescentes como sobrenomes em todas as outras línguas indo-européias (latinas, germânicas, célticas etc.), lembram e marcam a presença do pai toda vez que o nome do filho é pronunciado. Não podemos falar em Liev Nicolaievitch Tolstoi sem notar que seu pai se chamava Nicolai. Assim como os sufixos eslavos -vitch, -wicz, -vic, como em Pavlovitch, Petrowicz, Ivanovic, temos os sufixos ibéricos -es e -ez, como em Álvares, Peres, Esteves, Nunes, Vásquez, Ramírez, Rodríguez etc.; os sufixos germânicos -son, -sson, sen, -sohn, como em Peterson, Gunnarsson, Andersen, Johannsohn etc.; o sufixo grego -poulos, como em Dimitropoulos e Papadopoulos; o prefixo Fitz-, como 


\section{OBSERVANDO A \\ PSIQUIATRIA \\ ano IX, n. 2, jun/2006}

em FitzGerald, FitzPatrick, FitzJames, FitzWilliam etc., que se originou do franconormando fiz (de fils); os prefixos celtas O' e Mc, como em O'Brien, O'Connor, McGregor, McDonald etc. Nas línguas semíticas, temos os prefixos ibn- e ben-, que designam o nome do pai, como em ibn-Sina (que originou a transcrição Avicena), Ben-Bella, Ben-Gurion e Benjamin.

Assim, em seguida ao primeiro nome (ou nome de batismo, geralmente de origem bíblica), a lembrança do pai, ao lado da profissão tradicional da família ou do lugar de origem, era tradicionalmente sugerida na maior parte dos sobrenomes. Um forte vínculo entre religião, terra, trabalho e família criava um sentido de eternidade, como na expressão "retornar aos ancestrais", comum no oriente (Thursby, 1999).

\section{O tempo contínuo e a idade}

A sociedade moderna, tendendo ao individualismo (Dumont, 1991, Elias, 1994), fragmentou os ciclos familiares, o vínculo telúrico, os laços de origem e as tradições profissionais. São constituídas relações impessoais, estruturas burocráticas de poder e carreiras planejadas, que seguem uma linha inexorável: competição $\rightarrow$ ascensão $\rightarrow$ decadência $\rightarrow$ aposentadoria $\rightarrow$ morte. O mercado não mostrava interesse no idoso e a aposentadoria passou a ser compulsória, deixando de ser uma opção para as pessoas mais debilitadas ou para aqueles já sem condições de trabalho. Nos EUA, de acordo com Metge \& Cahn (2000), os salários representavam apenas $17 \%$ da renda dos maiores de 65 anos em 1986; em comparação, o Seguro Social fornecia $38 \%$ e os fundos de pensão outros $16 \%$. Isto reflete uma dramática diminuição na proporção de idosos empregados. Em 1948, mais de 50\% dos maiores de 65 anos estavam empregados, em comparação com apenas $16 \%$ dos homens e $7 \%$ das mulheres da mesma faixa etária em 1987.

Como o desenvolvimento do conhecimento inverteu a hierarquia do saber, e o jovem passou a saber mais que o idoso, o estabelecimento de um status econômico e social suficientemente elevado para permitir um envelhecimento condigno passou a ser condição sine qua non para permitir uma vida mental equilibrada (ver Krause et al., 1991; West et al., 1998). O nível de tensão na faixa limítrofe passou a ser muito grande. Na Austrália, de acordo com Hassed (2000), o nível de estresse em populações ocidentalizadas cresceu em 45\%. De acordo com Gardner et al. (1964) os pacientes deprimidos de 55 anos ou mais apresentam o dobro da taxa de suicídio dos deprimidos mais jovens. De acordo com Blazer (1995), o índice de suicídios entre os brancos do sexo masculino 


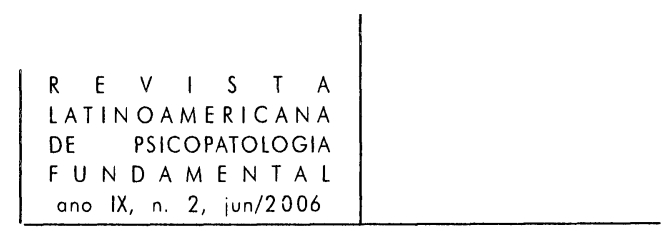

cresce enormemente na faixa entre os 50 e os 60 anos. Schmitz-Scherzer (1995) atribui aos valores individualistas o crescimento dos suicídios de idosos na Alemanha.

A impossibilidade de se desvincular afeto, responsabilidade e poder dentro da hierarquia familiar é um tema-chave no Rei Lear, de Shakespeare. A realidade clínica mostra que muitas famílias, hoje em dia, vivem pequenas tragédias muito semelhantes. A diferença é que em geral terminam de forma mais prosaica, em tribunais, asilos e medicamentos, sem nenhuma grandiloqüência.

Não muito estranhamente, uma nova entidade nosológica psiquiátrica, chamada "depressão" veio surgindo em proporções epidêmicas nas últimas décadas, de acordo com a OMS, e paulatinamente tomando o lugar da categoria psicopatológica do mesmo nome, muito mais restrita na sua versão anterior (KaslGodley, 1998).

$\mathrm{O}$ individualismo conduz também ao isolamento social dos improdutivos e assim o envelhecer nos asilos torna-se o destino inexorável de todos aqueles que já não conseguem mais manter a sua autonomia. Tudo o que lhes resta são a previdência social e os planos de saúde, para quem a idade é sinônimo de prejuízo, e o idoso se vê considerado um fardo para o sistema (Burgess, 1998).

\section{A perda do vínculo familiar e do pertencimento}

Como a proximidade da morte e o sentimento de perda não são suportáveis na sociedade globalizada consumista, nem há nenhuma forma de se encarar isso, a tragicidade da questão precisa ser negada a todo custo. "In America, dying is the most culturally obscene subject. We talk easily about sex, money, hate, and private family matters - but not about death" (Ebersole, 1990). Um enorme esforço é gasto para demonstrar que, com exercícios, bons hábitos e boa alimentação (além de hormônios e uma boa plástica), a velhice é um problema que tem solução. No cinema, vemos as atrizes européias de meia-idade e idosas apresentarem bravamente os sinais do tempo em seus rostos, com uma plástica aqui e outra ali. Já suas colegas americanas parecem bonecas louríssimas sorridentes e de olhos arregalados. Os cemitérios americanos são sempre belos e amplos jardins, onde absolutamente nada de lúgubre se sobressai para evocar a idéia da morte. Já os nossos velhos e sujos cemitérios mantêm um ar pesado e dramático, com suas inscrições chorosas ou solenes, e tudo à volta destacando a tragicidade da perda, o sofrimento e a fragilidade da condição humana.

Apesar da faixa média da mortalidade em geral ter aumentado em muito, a idade máxima do ser humano permanece mais ou menos a mesma. Como revelam 


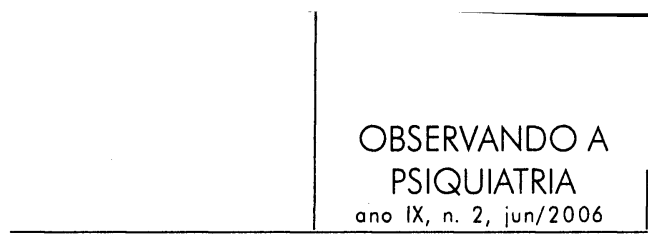

Olshansky e Carnes (2001), apesar de todo o estardalhaço da imprensa em torno dos progressos científicos sobre o envelhecimento, é muito pouco provável que a expectativa de vida humana venha a ultrapassar os 85 anos. $O$ que se conseguiu em todos estes anos de ciência médica foi reduzir a mortalidade infantil e as doenças infecciosas, deslocando as taxas mais altas de mortalidade da juventude para a velhice.

Assim, a busca da juventude eterna reorientou-se para a melhora da qualidade de vida do idoso. Nas palavras da Gerontological Society of America, a gerontologia deveria procurar "adding life to years, not just more years to life". No entanto, parece ser difícil encontrar algo mais do que hábitos saudáveis de vida e bem-estar econômico na perspectiva moderna de successful aging, e um fim como o de Abraão, cercado pela família, pleno de realizações e farto de dias, parece muito afastado no passado. As perdas pessoais, a queda na produtividade e no valor social, as diminuições nas capacidades físicas e cognitivas, as dificuldades face às inovações e alterações culturais, entre outras mazelas, deixam o idoso da sociedade individualista moderna numa posição muito pouco confortável (Cole, 1984 e 1991).

O conceito fenomenológico de depressão

$\mathrm{Na}$ perspectiva psicopatológica fenomenológica a depressão consiste em um estado de esvaziamento afetivo, de perda da energia vital, do entusiasmo, da motivação, da disposição de viver. O luto normal, a tristeza pela perda, o desânimo circunstancial pelas frustrações não devem ser incluídos nesta categoria. $O$ diagnóstico se submete aos critérios gerais do adoecer psíquico, tais como definidos por Karl Jaspers (1973) - reação, processo e desenvolvimento fazendo-se a discriminação entre as reações depressivas situacionais, os processos melancólicos (endógenos) e os desenvolvimentos depressivos da personalidade (os traços depressivos de caráter).

Como destaca Minkowski (1999), na depressão melancólica, dita endógena, vemos a predominância da inibição - do pensamento, da fala, da psicomotricidade etc. - enquanto nas depressões secundárias o que encontramos é um sentimento de impotência, de fragilidade, de incapacidade, sem que haja qualquer inibição real. Podemos acrescentar que aqui vemos com freqüência a ansiedade como sintoma predominante, acompanhada de estresse e sintomas psicossomáticos. Nas personalidades depressivas, no entanto, o que mais se destaca é o sentimento de dependência, com tendências à hipocondria e à manipulação dos vínculos afetivos. 


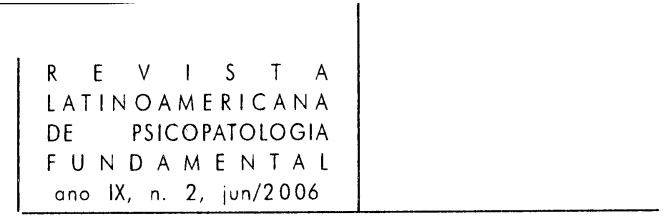

A construção sociocultural do conceito de depressão

A classificação nosológica - como todo e qualquer sistema classificatório é construída socialmente. Esta constatação nada tem a ver com o problema da sociogênese da doença, que é uma questão mais complexa e abrangente, e envolve o conceito de níveis patológicos.

Do ponto de vista da psicopatologia fenomenológica, não há nenhum problema nem com a construção social das classificações, pois sempre foram encaradas como aproximações mais ou menos objetivas a uma realidade essencialmente subjetiva; nem com a sociogênese, já que a multiplicidade causal faz parte de seus pressupostos. Ao mesmo tempo em que ocorria a passagem do psicologismo de orientação psicanalítica para o biologismo neuropsiquiátrico que observamos na história dos DSMs (Russo e Henning, 1999), a compreensão clínica psicopatológica foi cedendo lugar às classificações quantitativas e as escalas psicométricas foram substituindo o exame psíquico.

Particularmente, o que nos interessa destacar aqui é a medicalização da depressão, ou seja, a transformação de toda a dor, de todo o sofrimento humano em objeto da medicina, em brain disorder ou em alguma doença qualquer que pareça "real", objetiva e supostamente tratável pelos novos psicofármacos e pelas técnicas comportamentais.

\section{A depressão moderna}

De acordo com Alexopoulos $(1999,2001), 22 \%$ da população idosa apresenta sintomas depressivos, sendo que destes, $1 \%$ teria depressão "maior" e $4 \%$ transtornos de ajustamento com depressão. Huntley et al. (1986, apud Blazer, 1995) encontraram 15\% de depressivos na população de New Haven maior de 65 anos. Na Inglaterra, Copeland (1990, apud Blazer, 1995) achou 11,5\% em Liverpool, sendo $8,5 \%$ considerados neuróticos e $3 \%$ psicóticos. De acordo com Hassed (2000), na Austrália, 20\% dos adultos estão propensos a apresentar um quadro depressivo "maior" em suas vidas, e $16 \%$ dos maiores de 65 anos mostram sintomas persistentes. Van Marwijk et al. (1994) estimam em 17\% os quadros depressivos e em até $29 \%$ a presença de sintomas depressivos. Nos Estados Unidos, cerca de 11 milhões de pessoas ( 1 em 20, ou 5\%) são afetadas por depressão "maior" a cada ano. Cerca de $5 \%$ a $6 \%$ de americanos adultos experimentaram um transtorno depressivo maior durante um período de seis meses. Até $12 \%$ de todos os indivíduos podem requerer tratamento para depressão durante suas vidas. A prevalência do transtorno depressivo maior vai de $10 \%$ a 


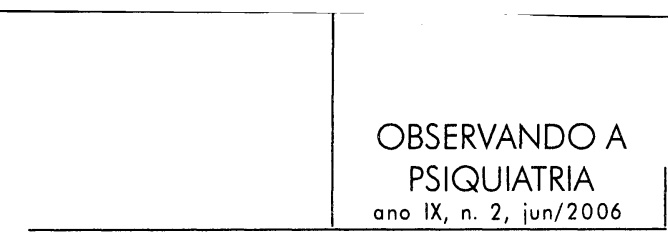

$25 \%$ para as mulheres e de $5 \%$ a $12 \%$ para os homens (Weissman et al., 1978; Myers et al., 1984; Regier et al., 1984, US Dep. of Health, 1993).

Mas essa insidiosa "doença" depressiva, encarada como uma estranha epidemia que atinge números enormes de pessoas hoje em dia (Zung, 1993), não deixa de ser uma criação bastante recente, ligada ideologicamente:

a. Como constructo cultural, ao culto individualista do sucesso, que tende a transformar automaticamente em loosers todos aqueles que não o alcançam.

b. Ao conceito moralista, puritano e fundamentalista do trabalho, que o encara como atividade sagrada, excluindo socialmente de forma automática todos os que não o cultuam, seja por falta de desejo ou de capacidade. O estar doente "de verdade" torna-se a única justificativa aceitável para o não-trabalhar.

c. Como forma de sofrimento psíquico, ao vazio existencial, à perda dos nexos afetivos com o grupo familiar e à perda dos vínculos com a terra, com as tradições e com o próprio sentido do trabalho.

d. Como entidade nosológica, ao cientificismo biologizante e à tendência à medicalização de todos os problemas da existência humana, que assim "explica" neurofisiologicamente todas as três situações anteriores, propondolhes automaticamente uma solução psicofarmacológica ou behaviorista, recondicionadora do comportamento.

\section{Antidepressivos versus estimulantes}

Drogas estimulantes como as anfetaminas já eram conhecidas desde a década de 1930 - e a cocaína desde o século XIX -, mas jamais foram usadas no tratamento da depressão, pois era fato conhecido que tendiam a piorar os quadros depressivos, favorecendo mesmo um aumento no risco de suicídio. Até a década de 1960, a eletroconvulsoterapia (ECT) era praticamente a única terapêutica eficaz para a depressão. No entanto, até essa época, o que se entendia por "depressão" eram apenas os chamados quadros "endógenos" ou psicoses afetivas, cuja prevalência nunca passou de aproximadamente $1 \%$. As depressões reativas e as neuróticas ou distímicas eram mais freqüentes, mas o tratamento recomendado era principalmente psicoterápico.

Os antidepressivos tricíclicos foram descobertos no fim da década de 1950 e até hoje não foram desbancados no tratamento dos quadros depressivos ditos "endógenos" ou "processuais". Nenhum antidepressivo mais recente se lhes iguala em eficácia quando essa diferenciação nosológica é feita com rigor, ou mesmo quando a gravidade do quadro entra em questão. Esta impressão clínica dos psiquiatras foi confirmada em diversos estudos europeus (e mesmo americanos), 


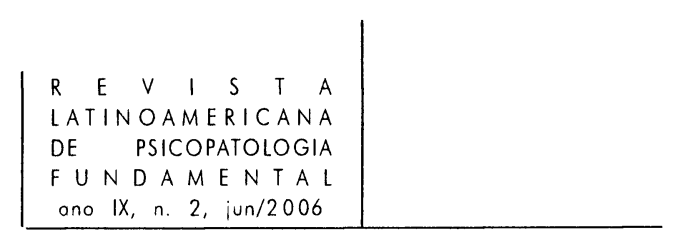

especialmente quando os quadros eram aqueles que exigiam internação, e para os quais não se encontrava qualquer relação de causa e efeito entre as manifestações psicopatológicas e os eventos externos ou história de vida do paciente. Quando a classificação behaviorista e quantitativa dos DSMs substituiu a observação fenomenológica, as diversas formas de depressão perderam qualquer aspecto diferencial entre si, exceto o número e a duração dos sintomas: assim hoje temos a depressão "maior" e a depressão "menor". Uma avaliação rigorosa reduziria a prevalência das atuais depressões maiores a níveis próximos dos $1 \%$ das antigas depressões endógenas, mas os critérios meramente quantitativos sempre permitem uma abrangência muito maior. Além disso, essa categorização permite a confusão entre sintomas de doenças orgânicas e de perda cognitiva. Como ressalta Blazer (1995): "DSM IV ... poorly differentiates psychiatric symptoms from those that signify the presence of physical illness and impaired cognition". Por causa dessa salada pseudo-objetiva que são os DSMs, mais voltados para fins jurídicos, administrativos e comerciais do que científicos, até mesmo psiquiatras de orientação fortemente biologizante, como van Praag (1998), os criticam: "Psychiatric taxonomy is currently based on invalid nosological premises..."

Essa abrangência exagerada permite que um número enorme de problemas, psiquiátricos ou não, acabe entrando no pacote da "depressão maior". Além disso, por exemplo, a clínica nos mostra que os quadros depressivos podem cursar, eventualmente, com manifestações paranóides, o que dificilmente permite a sua detecção pelos critérios do DSM IV, do CID-10 ou pelas escalas psicométricas como a de Hamilton ou CES-D. Isto ocorre porque estas sempre tendem a privilegiar o sintoma da culpa e a desprezar o da paranóia (Nikelly, 1988; Bastos, 1996).

Vemos que hoje em dia, porém, os estimulantes - incluindo até mesmo as próprias anfetaminas - têm largo uso na terapêutica de algo que também se chama "depressão". A explicação mais simples para esta aparente incongruência parece ser o fato de que o diagnóstico da depressão foi mudando completamente com os DSMs, tendo perdido toda a sua essência fenomenológica e psicodinâmica.

Até a década de 1970, os estados depressivos ou depressivo-ansiosos decorrentes de eventos da vida - tais como luto, aposentadoria, separações, desemprego, incapacidade, menopausa, doença ou abandono - eram classificados como depressões secundárias ou reativas e o uso de antidepressivos para esses casos não era recomendado em nenhum texto de terapêutica psiquiátrica. A menopausa é um bom exemplo disso (Robinson, 1996).

A partir da década de 1980, surgiram novos antidepressivos, cuja ação estimulante sobre esses quadros essencialmente reativos parecia ser mais eficaz e produzir menos efeitos colaterais. Criou-se então um enorme boom comercial e acadêmico na psiquiatria em torno dessas drogas, e assim, paralelamente, o 


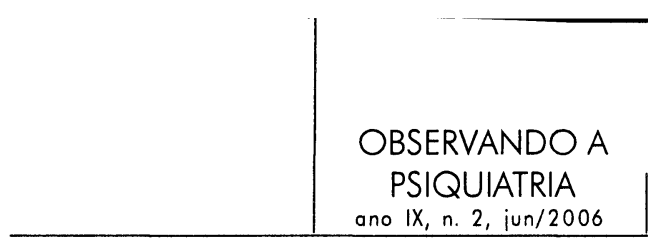

diagnóstico de depressão foi perdendo todo o seu caráter qualitativo, fenomenológico (distinguindo depressões processuais, depressões de personalidade e depressões reativas), para se tornar meramente quantitativo e comportamental (depressão maior ou menor, baseando-se na simples soma de sintomas). Assim, os novos estimulantes, chamados de antidepressivos, encontraram um imenso campo de aplicação na sociedade globalizada. Para a indústria farmacêutica, a década de 1990 foi a década da depressão. Entre 1991 e 2001, as vendas de drogas antidepressivas multiplicaram-se por dez, atingindo os onze bilhões de dólares e tornando esse setor o mais lucrativo de toda a indústria farmacêutica. Uma ilustração é o fato do mesmo laboratório lançar a mesma droga sob dois nomes de fantasia diferentes, por exemplo: um para tratar da depressão, outro, dos sintomas da chamada TPM e da menopausa, ou ainda um para tratar da depressão e outro do tabagismo.

Tanto a sua relativa ineficácia nas depressões processuais, a sua tendência a produzir estados de euforia com indiferença afetiva, como a sua propensão a induzir o suicídio foram escamoteadas das pesquisas, seja pelo fato de que tais casos de fracasso (geralmente nas "velhas" depressões) eram muito menos freqüentes do que as "novas" depressões, seja pelo mascaramento das amostras através de alguns "truques" de pesquisa. Vários trabalhos, geralmente europeus, demonstraram uma grande diferença de eficácia quando o grau (ou o tipo, dependendo de se usar critérios quantitativos ou qualitativos) da depressão era levado em conta.'

Ainda não contentes em considerar doente uma parcela significativa da população, muitos ainda procuram tornar patológica a presença de alguns sintomas isolados de depressão, produzindo a chamada "depressão subclínica", que, evidentemente, exige o mesmo tratamento (Lyness et al., 1999).

Todo esse movimento visava ampliar enormemente o escopo do tratamento psiquiátrico, criando uma ilusão de controle sobre os problemas da relação entre os indivíduos e a sociedade (Laplantine, 1991, Kleinman, 1985). Especialmente no que se refere aos psicofármacos, banalizou-se enormemente o seu uso, o que tornou os novos antidepressivos campeões de vendas. De acordo com David Healy (1997), ex-secretário da British Association for Psychopharmacology, "a idéia de que a infelicidade possa ser categorizada como doença e possa ser tratada

1. Por exemplo, os trabalhos do Danish University Antidepressant Group (Psychopharmacology 1986, 90, p. 131-8; Journal of Affective Disorders 1990, 18, p. 289-99, de S. M. Miller et al.: Acta Psychiatrica Scandinavica 1989, 80 (350), p. 143-4, de J. H. Heiligenstein (Journal of Affective Disorders, 1994, 30, p. 163-73), de Roose et al. (American Journal of Psychiatry 1994, 151, p. 1735-9). 


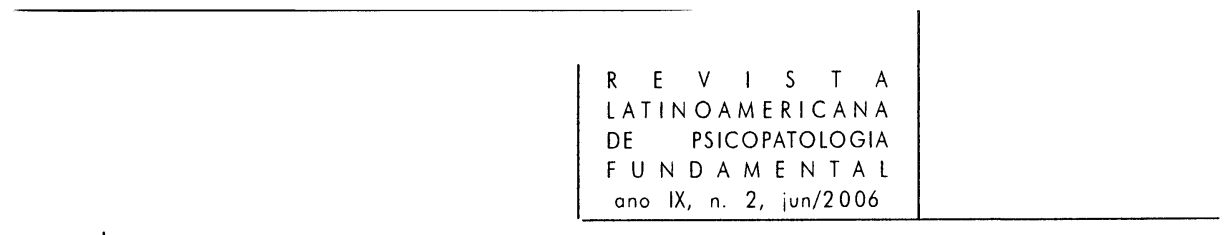 \\ com drogas" é um claro sinal da alienação da chamada "revolução psicofarmacológica". ${ }^{2}$ \\ Do isolamento social à depressão clínica}

A perda da vinculação a uma família, a uma terra e a um ofício, e o estabelecimento de uma programação individualizada, externa, de forma extrínseca, não natural e voltada apenas para os interesses da produção, deixa a cada ser humano uma única chance de ter um envelhecimento menos sofrido: naqueles casos em que o idoso consiga desfrutar de sucesso, bens e poder (George, 1995; Gall, 2001). Como tais casos são raros, evidentemente, só resta para grande parte da população idosa uma existência esvaziada de sentido, uma lenta e penosa espera da morte, na qual as velhas Moiras se vêem substituídas pelos burocratas, pelo managed care e finalmente pela eutanásia. Em mais um milagre da tecnologia, as novas Lachesis já podem medir o fio da vida pelo telefone: "Infelizmente, já se esgotaram os direitos do seu plano", o que é o mesmo que dizer: "Seus dias estão contados". Enquanto isso, as técnicas mais modernas de se pôr termo à existência vão sendo difundidas em livros e pela internet, e milhares de piedosos Drs. Kevorkians assumem pelo mundo o papel da ultrapassada Atropos. De acordo com Ingebretsen e Solem (1998), 60 a 80\% do público nos países ocidentais são favoráveis à eutanásia voluntária, se bem que esta opção seja menor entre os idosos (Waller, 1986, cit. ibid.). Encerrar uma vida sem perspectivas parece ser vista como uma boa alternativa para o paciente e para a família, além de ser, sem dúvida, uma excelente decisão do ponto de vista dos acionistas das seguradoras de saúde.

Como seria impensável que o novo way of life proposto pela sociedade globalizada pudesse jamais estar errado, concluiu-se forçosamente que o número crescente de pessoas desestimuladas e angustiadas deveria estar relacionado a alguma grave doença cerebral, que atingia proporções de epidemia, sendo chamada de "depressão". Como os neurotransmissores apresentavam-se alterados - aliás, como sempre se apresentam em todas as atividades mentais específicas - pela lógica do post hoc ergo propter hoc, decidiu-se que se tratava de uma disorder

2. O Dr. David Healy havia sido convidado para professor na Universidade de Toronto. Ousou fazer uma conferência crítica à indústria farmacêutica e logo foi "desconvidado". Houve grande celeuma no Canadá e a conferência foi posta à disposição do público interessado pela revista Nature (David Healy Lecture http://www.nature.com/nm/voting/intro.html). Agradeço a lembrança ao Dr. Walmor Piccinini. 


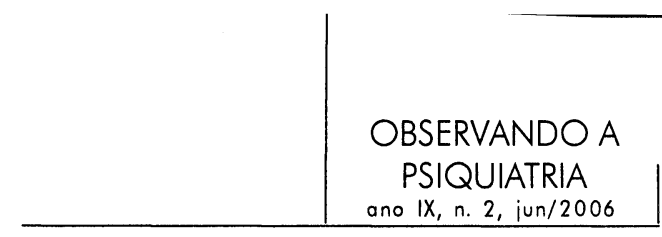

indubitavelmente originada por algum desequilíbrio de neurotransmissores. $\mathrm{O}$ fato de que nunca se conseguiu formular uma hipótese consistente para explicá-la, assim como a patente inespecificidade dos psicofármacos e dos neurotransmissores envolvidos em seu tratamento, não foi empecilho para que essa "teoria" fosse e continue sendo apresentada como científica em todas as instâncias. Transformou-se assim a mera infelicidade em uma doença médica, como bem disse Healy (1997).

\section{A concepção da temporalidade, o envelhecer e a depressão}

Como vimos, nas concepções culturais que tendem a perceber a passagem do tempo de forma predominantemente cíclica, o envelhecer é visto como parte de um movimento eterno, e a família se perpetua em seus descendentes, nas suas tradições, no cultivo da terra ou no exercício do ofício familiar. As transformações culturais que proporcionam a passagem para enfoques mais direcionais do tempo vão produzindo uma história social e destacando cada vez mais o papel individual nessa história. Quanto mais difícil for a passagem de uma Weltanschauung tradicional, de tendência circular, fatalista, repetitiva e eterna para uma outra individualizada, burocratizante, planejadora e sucessiva, mais difícil se torna a possibilidade de uma senectude satisfatória. Se ambas as perspectivas buscam a previsibilidade e o controle do destino, na segunda o fardo da decadência recai sobre o indivíduo, que deve planejar o fim da sua própria existência, se quiser suportá-lo com dignidade. O pragmatismo individualista americano reagiu ao aumento relativo e absoluto de idosos na população através da proposta de se alcançar o successful aging. Cole (1991) critica esse conceito, reconhecendo nele o problema implícito da velhice mal-sucedida, e denunciando a sua negação.

De acordo com Hazan (1994), na sociedade moderna ocorre uma ruptura entre o universo de significados do idoso e a sua capacidade de controlá-lo. Ele propõe quatro tipos de respostas: a primeira seria o abandono do controle, pelo isolamento e indiferença; a segunda seria a desistência do significado em favor do controle, com atitudes egocêntricas e socialmente inadequadas; a terceira seria o abandono de ambos, com a perda do desejo de viver; a última consistiria num ajuste do significado ao campo de controle ainda disponível, emprestando enorme importância a pequenas rotinas e rituais particulares. A repetição seria então uma forma de manter tudo como está. Assim, o objetivo último do idoso torna-se interromper a passagem do tempo que traz a decrepitude e a morte. De certa maneira, há sempre uma tendência a se retornar aos ciclos. 


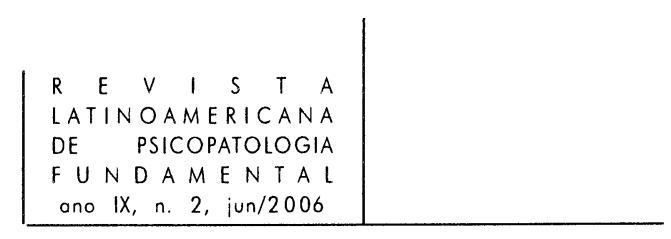

Nos aspectos em que os constructos modernos sobre a velhice ideal não satisfazem as necessidades da população idosa, assim como quando a sociedade transita entre modelos culturais diferentes, inúmeros problemas vão sendo criados, entre eles o vazio existencial, assim como também as suas "soluções": a medicalização da angústia, da decadência e da própria morte. Em populações em que escasseiam ou inexistem os substratos culturais que permitem a assimilação completa dessas propostas cria-se uma espécie de limbo onde o idoso fica psicologicamente desamparado e sem quaisquer referências, tendo perdido a inserção social e já não dispondo mais da familiar. Processos parciais de aculturação podem ocasionar situações de indefinição da identidade, deterioração dos valores, dos registros de memória (Candau, 1998), assim como esvaziar afetivamente os indivíduos (Swenson et al., 2000), produzindo estados depressivos e abundantes queixas somáticas. Shetterley et al. (1996) observaram uma clara discrepância entre o estado de saúde objetivo e o subjetivo em sujeitos hispânicos, comparados com brancos não-hispânicos.

Achamos que seria necessário investigar a importância das concepções temporais de tendência cíclica em pacientes idosos deprimidos de ambulatórios de psiquiatria de hospitais gerais. Sabemos que uma porcentagem extremamente alta - em torno de 50\% - da demanda total das instituições públicas de saúde apresenta quadros depressivo-ansiosos surgidos em momentos de declínio na vida social - como aposentadoria, separação, abandono pelos filhos etc. - gerando então sentimentos de rejeição, desvalorização e de falta de reconhecimento, construindo assim uma auto-imagem de decadência, deterioração e exclusão.

Poderíamos assim descobrir se nesse universo de queixosos de sintomas depressivos existiria alguma predominância daqueles cujas concepções sobre a continuidade e terminalidade da passagem do tempo vêm sendo mais radicalmente alteradas, assim como daqueles cujo universo cultural, cujos valores religiosos e familiares vêm perdendo importância ou sofrendo modificações essenciais. Seria também possível complementarmos a observação investigando também as possíveis correlações entre as apresentações dos sintomas psicopatológicos e as características de personalidade que promovam inclinações à internalização ou à externalização da responsabilidade.

Hendricks \& Hendricks (1976) alertam para a tendência a se procurar modelos em que se encaixem todos os idosos como categoria. Como perspectiva mais abrangente, lembram a tipologia de Mann, Siegler e Osmond (1972, apud Hendricks, 1976), baseada em Jung, que distingue os tipos de personalidade perceptiva, sentimental, pensativa e intuitiva. O primeiro tipo tenderia a viver só o presente; no segundo predominaria o passado, de forma circular; o terceiro tenderia a ligar os eventos no fluxo do tempo, de forma contínua; o último experimentaria o tempo como que de trás para frente, introjetando o futuro no 


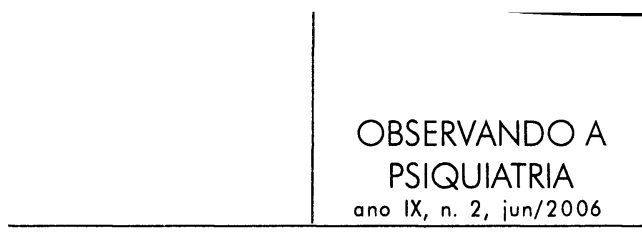

presente. Assim eles destacam a multidimensionalidade das experiências temporais, observando que as características de personalidade podem ser tão importantes como o próprio envelhecimento.

A construção de cada um dos múltiplos universos culturais tende a favorecer alguns aspectos mais específicos dos traços de caráter que se observam nas personalidades individuais. Assim, a observação fenomenológica não pode ser substituída na compreensão da participação da cultura nos eventos psicopatológicos.

\section{Referências}

Alexopoulos, G. S. Depression and other mood disorders. In: Geriatrics Review Syllabus, 4th ed. New York: American Geriatrics Society, 1999. p. 167-75.

BASTos, C. L. O tempo, as representações sociais de doença e a psicoterapia. Informação Psiquiátrica, v. 15, n. 4, p. 139-44, 1996.

Tempo, idade e cultura: uma contribuição à psicopatologia da depressão no idoso. Primera parte: Temporalidade e cultura. Revista Latinoamericana de Psicopatologia Fundamental, ano VIII, n. 4, p. 738-753, dez. 2005.

Tempo, idade e cultura: uma contribuição à psicopatologia da depressão no idoso. Segunda parte: Uma investigação sobre a temporalidade e a medicina. Revista Latinoamericana de Psicopatologia Fundamental, ano IX, n. 1, p. 89-113, mar. 2006.

Blazer, D. G. Epidemiology of psychiatric disorders in late life. In: Busse, E. W. \& Blazer, D. G. (org.). Textbook of Geriatric Psychiatry. 2nd ed. Washington: American Psychiatric Press, 1995.

Burgess, E. O.; Schmeeckle, M. \& Bengtson, V. L. Aging individuals and social contexts. In: Nordhus, I. H.; VANDenbos, G. R.; Berg, S. \& Fromholt, P. (org.). Clinical Geropsychology. Washington: American Psychological Association, 1998.

CANDAU, J. Mémoire et identité. Paris: PUF, 1998.

ColE, T. R. Aging, meaning and well-being: musings of a cultural historian. International Journal of Aging and Human Development, n. 19, p. 329-36, 1984.

The Journey of Life: A Cultural History of Aging in America. New York: Cambridge University Press, 1991.

Dumont, L. Essais sur l'individualisme. Paris: Éditions du Seuil, 1991.

Ebersole, P. Toward Healthy Aging: Human needs and nursing response. 3rd.ed. St. Louis: Mosby, 1990.

Elias, N. A sociedade dos indivíduos (Die Gesellschaft der Individuen). Rio de Janeiro: Zahar, 1994. 


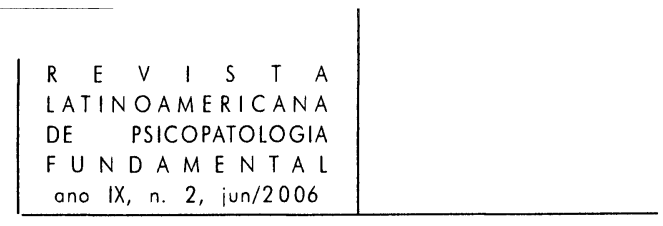

Gall, J. S. \& Swabo, P. A. Psychosocial aspects of aging. Geriatrics Reviews Syllabus, 1999-2001.

Gardner, E. A.; Balm, A. K.; Mack, M. Suicide and psychiatric care in the aging. Arch. Gen. Psychiatry, n. 10, p. 547-53, 1964.

GEORGE, L. K. Social and economic factors related to psychiatric disorders in late life. In: Busse, E. W. \& Blazer, D. G. (org.). Textbook of Geriatric Psychiatry. 2nd. ed. Washington: American Psychiatric Press, 1995.

Hassed, C. S. Depression: dispirited or spiritually deprived? Medical Journal of Australia, n. 173, p. 545-7, 2000.

Hazan, H. Old Age, Constructions and Deconstructions. Cambridge: Cambridge University Press, 1994.

Healy, D. The Anti-Depressant Era. Cambridge: Harvard University Press, 1997.

Hendricks, C. D. \& Hendricks, J. Concepts of time and the aged. In: Gubrium, J. F. (org.). Time, Roles and Self in Old Age. New York: Human Sciences Press, 1976.

Ingebretsen, R. \& Solem, P. E. Death dying and bereavement. In: Nordhus, I. H.; Vandenbos, G. R.; Berg, S. \& Fromholt, P. (org.). Clinical Geropsychology. Washington: American Psychological Association, 1998.

314 JAsPers, K. Psicopatologia geral (Allgemeine Psychopathologie). Rio de Janeiro: Atheneu, 1973. $2 \mathrm{vv.}$

Kasl-Godley, J. E.; GATZ, M. \& Fiske, A. Depression and depressive symptoms in old age. In: Nordhus, I. H.; Vandenbos, G. R.; Berg, S. \& Fromholt, P. (org.). Clinical Geropsychology. Washington: American Psychological Association, 1998.

Kleinman, A. \& Good, B. (org.). Culture and Depression. Berkeley: University of California Press, 1985.

Krause, N.; JAY, G.; LiAN, G. Financial strain and psychological well-being among the American and Japanese elderly. Psychology and Aging, v. 6, n. 2, p. 170-81, 1991.

Laplantine, F. Antropologia da doença (Anthropologie de la Maladie). São Paulo: Martins Fontes, 1991.

Lyness, J. M.; King, D. A.; Cox, C.; Yoediono, Z.; Caine, E. D. The importance of subsyndromal depression in older primary care patients: prevalence and associated functional disability. Journal of the American Geriatric Society, v. 47, n. 6, p. 647-52, 1999.

Metge, C. J. \& Cahn, B. Health Policy. In: Ruskin, P. E. \& Rogers, E. L. MEGA Multidisciplinary Education in Geriatry \& Aging. Baltimore: University of Maryland, 2000.

Minkowskı, E. Traité de psychopathologie. Collection Les Empêcheurs de Penser en Rond. Synthélabo. Le Plessis-Robinson, 1999. 
Myers, J. K.; Weissman, M. M.; Tischler, G. L. et al. Six-month prevalence of psychiatric disorders in three communities: 1980-1982. Archives of General Psychiatry, n. 41, p. 959-67, 1984.

Nikelly, A.G. Does DSM-III-R diagnose depression in non-Western patients? International Journal of Social Psychiatry Winter, v. 34, n. 4, p. 316-20, 1988.

Olshansky, S. J. \& Carnes, B. A. The Quest for Immortality: Science at the Frontiers of Aging. New York: W. W. Norton, 2001.

Regier, D. A.; Myers, J. K.; KrAmer, M. et al. The NIMH Epidemiologic Catchment Area program: historical context, major objectives, and study population characteristics. Archives of General Psychiatry, n. 41, p. 934-41, 1984.

Robinson, G. Cross-cultural perspectives on menopause. Journal of Nervous and Mental Disease Aug, v. 184, n. 8, p. 453-8, 1996.

Russo, J. \& HenNing, M. F. O sujeito da "psiquiatria biológica" e a concepção moderna de pessoa. Antropolítica, n. 6, p. 39-55, 1999.

ScHMITZ-Scherzer, R. Reflections on cultural influences on aging and old-age suicide in Germany. International Psychogeriatrics Summer, v. 7, n. 2, p. 231-8, 1995.

Shetterly, S. M.; Baxter, J.; Mason, L. D.; Hamman, R. F. Self-rated health among Hispanic vs non-Hispanic white adults: the San Luis Valley health and aging study. American Journal of Public Health, v. 86, n. 12, p. 1798-801, 1996.

Swenson, C. J.; Baxter, J.; Shetterly, S. M.; Scarbro, S. L.; Hamman, R. F. Depressive symptoms in Hispanic and non-Hispanic white rural elderly: the San Luis Valley health and aging study. American Journal of Epidemiology, v. 152, n. 11, p. 1048-55, 2000.

Thursby, G. R. Aging in Eastern traditions. In: Cole, T. R.; Kastenbaum, R. \& Ray, R. (org.). Handbook of Aging and the Humanities. New York: Springer, 1999.

U.S. Department of Health and Human Services. Depression in Primary Care: Volume 1. Detection and Diagnosis. AHCPR Publication n. 93-0550, Clinical Practice Guideline n. 5, 1993.

van Marwijk, H.; Hoeksema, H. L.; Hermans, J.; Kaptein, A. A.; Mulder, J. D. Prevalence of depressive symptoms and depressive disorder in primary care patients over 65 years of age. Family Practice, v. 11, n. 1, p. 80-4, mar. 1994.

van PraAg, H. M. The diagnosis of depression in disorder. Australian and New Zealand Journal of Psychiatry, v. 32, n. 6, p. 767-72 e discussion p. 773-7, 1998.

Weissman, M. M.; Myers, J. K. Affective disorders in a US urban community: the use of research diagnostic criteria in an epidemiological survey. Archives of General Psychiatry, n. 35, p. 1304-11, 1978.

West, C. G.; Reed, D. M.; Gildengorin, G. L. Can money buy happiness? Depressive symptoms in an affluent older population. Journal of the American Geriatric Society, v. 46, n. 1, p. $49-57,1998$. 


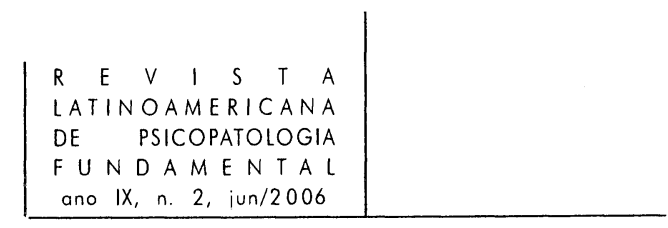

Zung, W. W.; Broadhead, W. E.; Roth, M. E. Prevalence of depressive symptoms in primary care. Journal of Family Practice, v. 37, n. 4, p. 337-44, 1993.

\section{Resumos}

Procuramos aquí relacionar dos aspectos fundamentales de las intuiciones culturales sobre el pasaje del tiempo - la temporalidad cíclica e a continua - con la terapéutica médica y más especialmente con la psicopatología, en una visión critica del constructo moderno de la depresión en la vejez. Inspirado en perspectivas antropológicas, el texto busca apoyo en la experiencia clínica diaria y en la actitud fenomenológica que la orienta. Para las concepciones culturales del tiempo que tienden a percibir su pasaje de forma predominantemente cíclica, envejecer es parte de un movimiento eterno, la familia se perpetúa en sus descendientes, en sus tradiciones, en el vínculo con la tierra o en el ejercicio del trabajo familiar. Las transformaciones culturales que han proporcionado el pasaje para enfoques más direccionales del tiempo van destacando cada vez más el rol individual en la historia social. Cuanto más dificultoso sea el pasaje de Weltanschauungen tradicionales, de tendencia circular, fatalista, repetitiva y eterna, para otras, de tendencia individualizante, burocratizante, planeadora y sucesiva, más grandes las dificultades para una senectud satisfactoria $y$ mayor la tendencia a la medicalización de este fracaso. Esta es la tercera parte de una serie de tres artículos.

Palabras claves: Psicopatología y cultura, temporalidad y medicina, depresión en el anciano, psicogeriatría

Nous cherchons ici à relationer deux aspects fondamentales des conceptions intuitives culturelles sur la passage du temps - la temporalité cyclique e la continue - avec la thérapeutique médicale et plus spécialement avec la psychopathologie, dans une vision critique de la conception moderne de la dépression chez la vieillesse. Inspirée des perspectives anthropologiques, le texte se soutier dans l'expérience clinique de chaque jour et dans l'attitude phénoménologique guidant cette pratique. Dans las conceptions culturelles du temps de tendance cyclique, le vieillissement est part d'un mouvement éternel et la famille se perpétue par ses descendants, sas traditions, ses liens avec la terre ou l'exercice du métier familier. Les transformations culturelles que proportionnent la passage pour un approche plus directionnel du temps détachent de plus em plus le rôle individuel das l'histoire social. La plus difficile est la passage des perspectives traditionnelles, tendants à la circularité, à la répétition, au fatalisme et à l'éternité, pour autres de tendance à l'individualisation, à la bureaucratie, à la planification et à la succession, les plus grandes les entraves à une vieillesse 


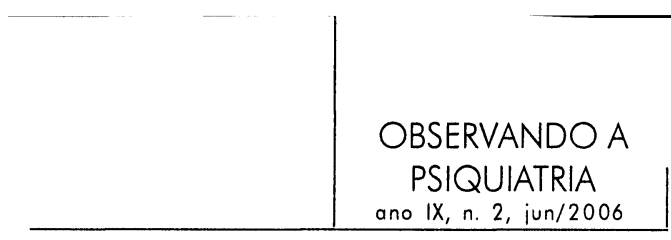

satisfaisante et la tendance à la médicalisation de ce problème. Cet article est la troisième part d'une série de trois.

Mots clés: Psychopatologie et culture, temporalité et médicine, depression et l'âgée,

psychogeriatrie

Two fundamental aspects of intuitive cultural conceptions of the passage of time - cyclical and continuous - are related here to medical therapy and psychopathology, from a critical perspective of the condition of depression in old age as a modern construct. Although inspired by anthropological perspectives, this article is based on daily clinical experience and takes a phenomenological attitude. In predominantly cyclical cultural perceptions of time the ageing process is part of an eternal movement, and families perpetuate themselves in their descendants, their traditions, ties with the land, or in the practice of family crafts and skills. Cultural transformations that give rise to more directional approaches to the passage of time tend toward growing emphasis on individual roles in social history. The more difficult the change from fatalist, repetitive, traditional and eternally cycling Weltanschauungen, on the one hand, to others, based on individualizing, bureaucratizing, planning-based and successive concepts, the greater are the chances of unsuccessful old age and the medicalisation of this failure. This paper is the new of a three-part series.

Key words: Psychopathology and culture, temporality and medicine, depression and ageing, psychogeriatrics

Versão inicial recebida em dezembro de 2005

Versão revisada recebida em abril de 2006 